\title{
Drug use and criminality among unaccompanied refugee minors: a review of the literature
}

\author{
Anna-Karin Ivert and Mia-Maria Magnusson
}

\begin{abstract}
Purpose - Organisations working with children have acknowledged that unaccompanied refugee minors (URM) across Europe are exposed to environments and situations that put them at risk for becoming addicted to drugs or becoming involved in crime. The purpose of this paper is to study an examination of existing international research concerning URM and of whether, and if so how, issues relating to drug use and criminality among these children are discussed in the international literature.

Design/methodology/approach - A literature review was conducted using PsycINFO, PubMed, Sociological abstracts and ERIC databases, which together cover the social and behavioural science and also medicine.

Findings - Findings from the present review show that the issues of drug abuse and criminality among URM are rarely acknowledged in the international research literature. When the occurrence of substance abuse and/or criminality is discussed, it is often in relation to mental health problems and in terms of self-medication, i.e. that alcohol or drugs are used by the URM to cope with painful experiences or mental health problems, and also with the challenges of integrating into a new society, difficulties finding work, unsuitable living conditions and a lack of social support.

Originality/value - This review shows that several researchers have emphasised that untreated mental health problems, stressful living conditions and a lack of support and control might put these children at risk for substance abuse and criminality, and this suggests a need for further research in this area.
\end{abstract}

Keywords Review, Drug use, Criminality, Unaccompanied refugee minors

Paper type Literature review

\section{Introduction}

Over the last decade, the number of unaccompanied minors applying for asylum in Europe has increased significantly, and Sweden and Germany have together received a majority of these children (Eurostat, 2018; Swedish Migration Agency, 2018). The experiences and life circumstances of these children have been a subject for discussion among politicians, professionals, the media and researchers. Over recent years the phenomena of drug use and criminality among unaccompanied refugee minors (URM) have attracted increased attention in the public debate in Sweden (Nordgren, 2017; Wagner, 2017). These issues have also been acknowledged by various Swedish authorities, and in 2017 the Swedish government decided to instruct the Public Health Agency of Sweden, in collaboration with the National Board of Health and Welfare, to investigate drug use among unaccompanied children and young persons in Sweden. This investigation reported that although no conclusions could be drawn about the magnitude of the problem, substance abuse does occur and needs to be acknowledged (Folkhälsomyndigheten, 2017).

International organisations such as UNICEF have also acknowledged that refugee children across Europe are exposed to environments and situations that put them at risk for becoming addicted to drugs or becoming involved in crime (Beise et al., 2017; Digidiki and Bhabha, 2017).
Anna-Karin Ivert and Mia-Maria Magnusson are both based at the Department of Criminology, Fakulteten för hälsa och samhälle, Malmö universitet, Malmo, Sweden.
Received 20 May 2019 Revised 16 August 2019 Accepted 4 October 2019 (C) Anna-Karin Ivert and Mia-Maria Magnusson. Published by Emerald Publishing Limited.

This article is published under the Creative Commons Attribution (CC BY 4.0) licence. Anyone may reproduce, distribute, translate and create derivative works of this article (for both commercial \& non-commercial purposes), subject to full attribution to the original publication and authors.

The full terms of this licence may be seen at: http://

creativecommons.org/licences/by/ 4.0/legalcode 
In Sweden, drug abuse and criminality have been noted by authorities as constituting risk behaviours in URM in connection with children running away and going missing (Länsstyrelsen, 2016). The Swedish Ombudsman for Children has reported that some of the children who run away end up on the street and in contexts in which they are exposed to abuse, criminality and drugs (Barnombudsmannen, 2017). This is confirmed by reports from the Swedish Police, which state that the police have seen an increase in URM who engage in crime and spend time in social settings characterised by drug dealing and drug use (Pettersson, 2016). In addition, the Swedish National Board of Institutional Care (SiS) has witnessed an increase in the number of URM being placed in their care, and for a majority of these children substance abuse and/or externalising behaviour were stated as reasons in the placement applications (Kaunitz and Jakobsson, 2016).

While it is important to emphasise that only a minority of all URM are engaged in substance abuse or criminality, the reports mentioned above underscore the need for better collaboration between authorities and improved knowledge to better meet the needs of these children and young persons.

Against this background it would appear to be important to summarise how substance abuse and criminality among URM have been addressed and discussed in the international research literature. The present study therefore aims to provide an overview of the current knowledge on substance abuse and criminality among unaccompanied refugee children, the contexts/ situations associated with substance abuse and criminality and how these problems are acknowledged and responded to in the countries of resettlement.

\section{Background}

In research, the public debate and policy documents, URM are often categorised as a single group. This group is however characterised by a significant degree of heterogeneity in terms of demographic factors such as age, gender and ethnicity, and also in terms of their past and current experiences. Despite these differences, they also share a number of common characteristics, such as the experience of being separated from their parents or caregivers and the migration experience.

URM[1] are defined by the UNHCR as individuals under the age of 18 "[...] who are separated from both parents and are not being cared for by an adult who by law or custom is responsible to do so" (UNHCR, 1994). From a European perspective, URM are a group of migrants or asylum seekers that have grown dramatically over recent decades, and particularly over the last five years. The number of applications for asylum increased from 12,540 in 2012 to over 95,000 in 2015, and although the figures have declined significantly since then, there were still almost 31,800 URM seeking asylum in Europe in 2017 (Eurostat, 2018). Asylum applications by unaccompanied children have however been inequitably distributed across the EU states, with Sweden, together with Germany, registering more than 50 per cent of all unaccompanied minor asylum applicants in the EU between 2012 and 2016. In 2016 and 2017 the number of such applications registered in Sweden and Germany declined as a consequence of increased border controls, both at the national and the EU level (Andersson, 2016), and in 2017 the number of applicants in Sweden was at the same level as a decade ago (Eurostat, 2018; Swedish Migration Agency, 2018).

The international research on URM covers a variety of different areas such as physical health and screening for different types of diseases (Marquardt et al., 2016; Williams et al., 2016), age estimation (Thevissen et al., 2012) and the structure of care and reception processes (Derluyn and Broekaert, 2008; Wimelius et al., 2017). Further, there is research that explores the everyday life of URM and research that emphasises the need to listen to the minors own voices in order to better understand their experiences in the resettlement countries (Lundberg and Dahlquist, 2012; Malmsten, 2014; Wernesjö, 2014; Herz and Lalander, 2017). In addition to studies aimed at illuminating the perspectives and experiences of the minors themselves, there is research focused on the professional perspective. This research includes, for example, studies of police officers' and social workers' experiences of the forced repatriation of URM (Hansson et al., 2015; Sundqvist et al., 2016), social workers' views on how their practice can help unaccompanied children resettle in a new context ( Kohli, 2006), and Migration Agency case 
officers (Hedlund, 2017). There is also research investigating the ambiguous narratives and discourse of URM, how stereotypical ideas are re-constructed, reproduced and re-established in media and public debate (e.g. Stretmo, 2014), and how this can result in URMs being considered as problematic migrants and a potential threat to the destination country (Bryan and Denov, 2011; Uehling, 2008). This have also been investigated in relation to how the minors respond to the public discourse and how this influences their feelings of, for example, belonging and deservingness (Stretmo, 2014; Wernesjö, 2019).

However, the main focus of the literature has been directed at mental health related problems. The findings from most of these studies show that URM constitute a particularly vulnerable group with regard to problems such as post-traumatic stress disorder, depression and anxiety (Derluyn et al., 2009; Fazel et al., 2012; Sourander, 1998), and that these problems are still present years after resettlement (Bean, Mooijaart, Eurelings-Bontekoe and Spinhoven, 2007; Bean, Eurelings-Bontekoe and Spinhoven, 2007; Jakobsen et al., 2014; Jensen et al., 2014). This increased vulnerability is often explained by the minors' experiences of loss of family and friends, by trauma prior to and during their flight, or by a stressful asylum process and a fear of deportation (Derluyn and Broekaert, 2007, 2008; Fazel et al., 2012).

Less attention has been directed at how URM mental health is influenced by experiences of e.g. racism and discrimination, and how these experiences influence their life situation in the host country (Wernesjö, 2011). There are however studies that emphasise the association between daily "hassles" in the country of resettlement and depressive symptoms among unaccompanied children (Keles et al., 2016; Seglem et al., 2014), and which argue that both general hassles (e.g. economic hardship) and acculturation-specific hassles (e.g. discrimination) are important for understanding depression in this group (Keles et al., 2016).

Although a great deal of research on URM has focused on the problems and difficulties that they face, there has been a shift towards studies that focus on resilience, coping capacities and the strengths of this group (Eide and Hjern, 2013; Kohli, 2006; Raghallaigh and Gilligan, 2010; Seglem et al., 2014). In a study on labour market incorporation among refugee youth who arrived in Sweden as URM, Çelikaksoy and Wadensjö (2017) show that this group demonstrates both capacity and resilience in terms of finding employment and having a willingness to work. The authors argue that this might be explained by the fact that URM in Sweden receive a relatively high level of support, or by what has been termed a "healthy migrant" effect, i.e. that the group is comprised of individuals who are positively selected in terms of having high levels of potential and ability. Positive developments have also been associated with factors such as the use of healthy coping mechanisms, religiosity, involvement in prosocial organisations and a positive outlook (Carlson et al., 2012; Raghallaigh and Gilligan, 2010).

Viewed across the life course, adolescence is the period during which most people try drugs and alcohol for the first time, and when involvement in crime peaks (e.g. Moffitt, 1993; Piquero et al., 2013). However, not all adolescents are equally inclined to drug use and criminal behaviour, since individuals differ in crime propensity and vulnerability as well as to the extent to which they are exposed to criminogenic settings (e.g. Wikström et al., 2012). The research literature summarised above touches upon several factors that might have an impact on both individual development and exposure to criminogenic settings. For example, the association between substance abuse and mental health problems is well documented (e.g. Armstrong and Costello, 2002; Hawkins, 2009; Hodgins et al., 2010), and it has been argued that drugs are used as means of self-medication to ease, e.g. anxiety or stress among refugees and migrants (Dupont et al., 2005). Previous research has also identified an association between mental health problems and involvement in crime, with this association being more pronounced among children/individuals with externalising problems, although it has also been identified in relation to internalising problems (e.g. Aebi et al., 2014; Ivert et al., 2017; Loeber et al., 1998). In addition, it might be argued that the absence of close family members in their lives would decrease URM' access to social support and control, factors which have been shown to work as protective factors in relation to both substance abuse and involvement in crime (e.g. Dishion and Loeber, 1985; Svensson, 2003). However, even if URM do not have close family members with them in the country of resettlement, their families may still be a source of support, and they may also have, or desire, other important relationships (Herz and Lalander, 2017) that can serve both to provide 
social support and exert social control (Eide and Hjern, 2013). Furthermore, there are studies indicating that URM are resilient, have high ambitions and cope with their situation in a positive way (Çelikaksoy and Wadensjö, 2017; Kohli and Mather, 2003; Raghallaigh and Gilligan, 2010), characteristics that might serve as protection in relation to an antisocial development.

Even if Europe in general is witnessing a decline in the number of URM applying for asylum (with the exception of Italy and Greece), the rights and well-being of the children that have already arrived will continue to constitute an important challenge for the EU states in the coming years (Raghallaigh and Thornton, 2017).

\section{Selection of research for review}

To identify scientific articles on the subject of drug/substance (ab)use and criminality among URM, an extensive literature search was carried out. To identify research from different disciplines, searches were conducted in the PsycINFO, PubMed, Sociological abstracts and ERIC databases, which together cover the social and behavioural science and also medicine. The following keywords have been used: unaccompanied OR separated AND children OR minors OR youths OR adolescents AND migrant OR refugee OR asylum-seeking OR immigrant. This initial search was intentionally very broad, with the aim being to identify as many articles as possible. The search was however restricted to peer-reviewed journal articles published in English over the past 10 years (2007-2017). This search resulted in 425 articles, and following the removal of duplicates, 299 articles remained. All titles and abstracts were examined to arrive at a first selection of relevant articles. At this stage, only studies that clearly did not fall within the scope of this review were excluded (mainly studies that did not after all focus on URM). In the next step, full text searches were conducted using the terms drug, alcohol, substance, abuse, crime, criminality, offending, violence, delinquency, deviant behaviour and antisocial behaviour. A generous approach was also applied at this stage, with a focus on inclusion rather than exclusion. Nevertheless, about 75 per cent of the articles were excluded during this phase because they did not mention any of the above search terms, or if they did, they were used in relation to, e.g. criminal law and age assessments. As a final step, the 49 remaining articles were reviewed to examine whether the issues of URM drug/substance (ab)use and/or criminality in the resettlement country were addressed in any way. In this final phase, the reasons for excluding studies were, for example, that the articles discussed issues related to drugs or criminality in the minors' country of origin (Figure 1 presents the selection process step by step).

In total 25 articles were selected for inclusion in the review. Of these 25 articles, the majority investigated different aspects of the life circumstances of URM in European countries, and almost 50 per cent had been published during the last three years (see Table I for an overview).

A full text analysis of the selected articles was conducted to identify how issues on drug/substance (ab)use and/or criminality in the resettlement country were addressed. Based on the findings from the full text reading categories were developed inductively and discussed between the authors. As the material was synthesised, three different overarching themes were identified. These themes were: the occurrence, or non-occurrence, of substance abuse and criminality;, contexts associated with drug use and criminality; and the importance of appropriate care. Below, findings are presented in relation to these three overarching themes.

\section{Findings}

This overview is dominated by research that examines different issues related to the occurrence and development of mental health related problems within this group. Many of these studies apply a medical or psychological approach and these are often based on quantitative methods using self-report questionnaires or register-based data. However, there are also a number of studies from the social sciences, which often employ a qualitative approach and examine the children's experiences of their life circumstances. In addition to these empirical studies, the material also contains commentary articles. 


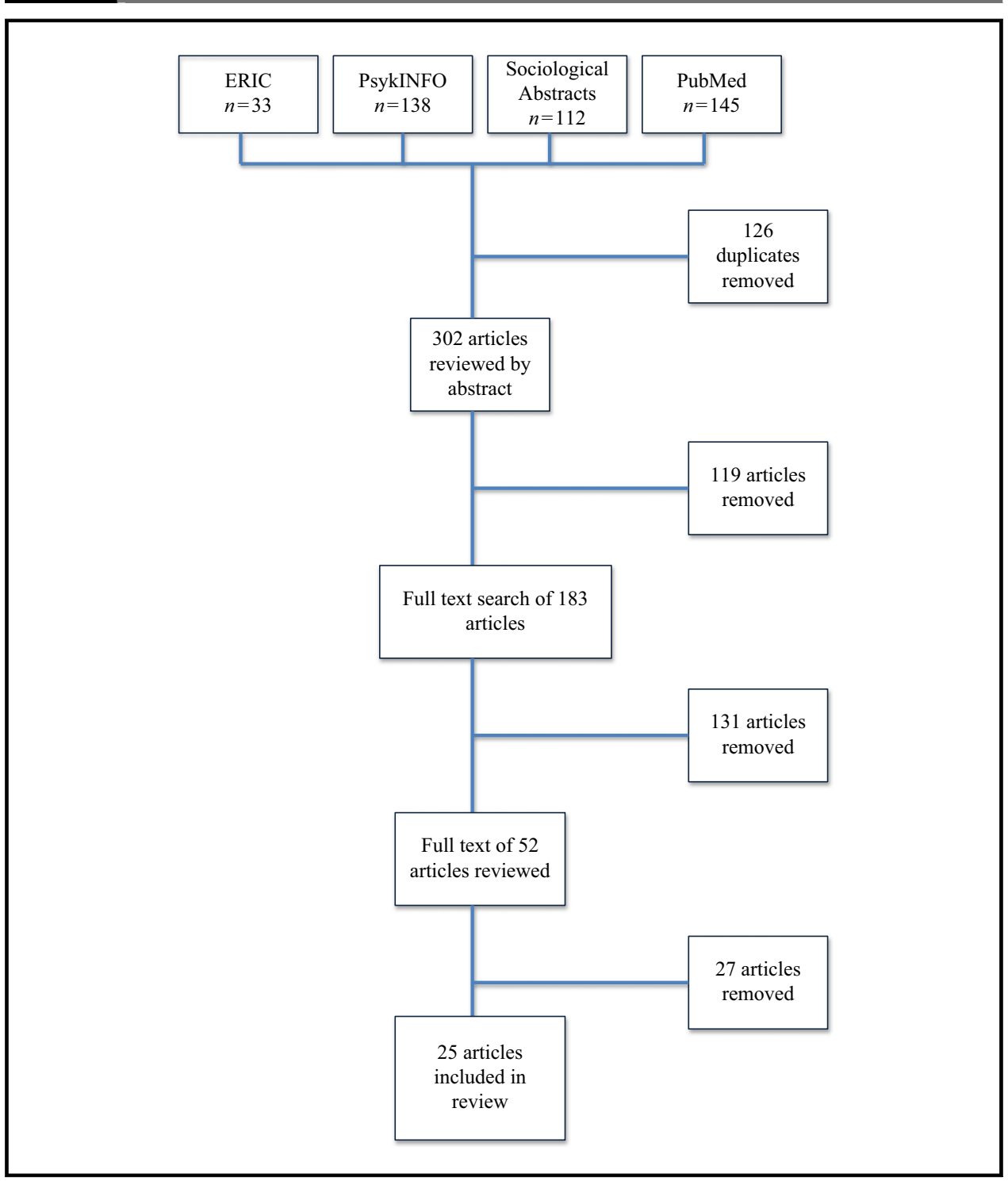

Before moving on to summarising the literature, it should be emphasised that with the exception of Manhica et al. $(2016,2017)$, none of the studies included in the present review have had the examination of substance abuse and/or criminality as their principal objective. Substance abuse and/or criminality are rather included as one dimension on a scale measuring the occurrence of mental health problems or as something that is mentioned in passing in a more general discussion of the experiences and challenges of the minors' everyday lives. In addition, the term criminality is seldom used in the included studies, the term externalising, or antisocial behaviour, is more common. However, items related to criminal acts like theft or violence are often used as measure externalising behaviour.

\section{Occurrence, or non-occurrence, of substance abuse and criminality}

A majority of the studies in this review that assess substance abuse and/or criminal behaviour use different types of questionnaires or structured interviews (e.g. Youth Self-Report (YSR), Child Behaviour Checklist (CBCL) or HSCL-25/37). These studies rely on self-, teacher- or social worker reports, and items assessing drug abuse and criminality or delinquency are included in scales measuring conduct problems or externalising behaviours (e.g. Derluyn et al., 2009; 
Table I Overview of included articles

Auger-Voyer et al. (2014)

Spain (Canary Island)

Bean et al. (2007a, b)

The Netherlands and Belgium

Bean, Mooijaart, Eurelings-Bontekoe and Spinhoven (2007)

The Netherlands

Derluyn and Broekaert (2007)

Derluyn et al. (2008)

Derluyn et al. (2009)

Belgium

Belgium

Deveci (2012)

Given-Wilson et al. (2016)

Herz and Lalander (2017)

Huemer (2009)

Huemer (2011)

Huemer et al. (2013)

Jensen (2015)

Luster et al. (2010)

Magqibelo et al. (2016)

Belgium

UK (discussion)

UK (review)

Sweden

Sweden (Comment)

Austria

Austria

Norway

USA

Manhica et al. (2017)

South Africa

Manhica et al. (2016)

Sweden

Marquardt et al. (2016)

Sweden

Germany

Nordgren (2017)

Sweden

Norström and Gustafsson (2010)

Sweden

Oppedal and Idsoe (2012)

Qin et al. (2015)

Norway

Raghallaigh and Thornton (2017)

Ramel et al. (2015)

Thommessen (2013)

USA

Sweden

Italy

Huemer et al. , 2011; Oppedal and Idsoe, 2012; Thommessen et al., 2013) . Some of the studies focus on evaluating the extent to which these instruments can be used for screening for mental health problems among URM (e.g. Bean, Mooijaart, Eurelings-Bontekoe and Spinhoven, 2007; Bean, Eurelings-Bontekoe and Spinhoven, 2007; Bean et al., 2007b).

A Norwegian study of conduct problems and depression among URM found that the level of self-reported antisocial conduct problems (property delinquency and violence) was very low, while levels of depression tend to be high in this group (Oppedal and Idsoe, 2012). The authors hypothesise that the developmental context that these children and youths share - travelling and resettling by themselves, with no caretaker - might enforce regulation processes that are important when it comes to handling aggression in order to avoid getting into trouble in ways that might jeopardise their asylum process and future residence status. Derluyn and Broekaert (2007) present a similar line of reasoning in a discussion of findings showing that self-reported externalising problems are less common than internalising problems, and also that they occur at lower levels than among refugee adolescents who live with their parents. The authors suggest that this might be a result of the "hard struggle of URM to reach a new future, through (amongst many other things) avoidance of misbehaviour" (Derluyn and Broekaert, 2007, p. 155).

Low levels of substance use were found by Huemer et al. (2011) in a study of unaccompanied African minors in Austria. In their sample, none of the 41 minors included in the study scored for substance use or substance dependence (measured using the M.I.N.I. Kid interview). This is a finding that appears to have surprised the authors, as did the finding that levels of emotional and behavioural functioning assessed using the YSR were the same as those of the general population in Austria. The authors discuss whether these findings might be a consequence of language difficulties among the minors, or of the minors hesitating to report symptoms that are interpreted as undesirable - either because they are associated with antisocial behaviour or because they might be interpreted as a sign of weakness or vulnerability. A Norwegian study (Jensen et al., 2015) that examined mental health among newly arrived URM (aged 16 or younger) omitted items related to substance abuse from its measure of externalising problems due to the young age of the participants. However, in reviewing their results the authors argue 
that the low levels of externalising problems found in their sample might be a consequence of having omitted the drug and alcohol related items. The findings, which show low levels of externalising or conduct problems among URM, are repeated in several studies that use scales comprised of items measuring substance abuse and delinquent behaviour, although these other studies do not present these items separately (Bean et al., 2007a; Derluyn and Broekaert, 2007; Derluyn et al., 2008; Huemer et al., 2013).

Another recurrent finding in these studies is a high level of internalising problems. In addition, in those cases where the studies have included a control group comprising either native and/or accompanied refugee/migrant children, the control group often scored higher than the URM with regard to externalising behaviours (including substance use and delinquency) (e.g. Bean et al., 2007a; Derluyn et al., 2008). By contrast, most studies have found that unaccompanied children scored higher on internalising problems than the control group (Bean et al., 2007a; Bean, Mooijaart, Eurelings-Bontekoe and Spinhoven, 2007; Bean, Eurelings-Bontekoe and Spinhoven, 2007; Derluyn et al., 2009).

Studies presenting results on externalising behaviours, including measures of delinquency, based on reports by social workers show that they tend to report higher scores on items measuring externalising behaviours than those reported by the unaccompanied children themselves (Derluyn and Broekaert, 2007). Thommessen and colleagues (2013) found higher levels of not only internalising problems but also externalising problems in a group of URM by comparison with native Italian adolescents. This study employed the $\mathrm{CBCL}$, and a social worker or parent was asked to rate the occurrence of, among other things, delinquent and aggressive behaviour. The authors discuss whether the observed differences might in part be explained by the parents being less willing to report problems in their children than the social workers, who instead have a professional relationship to the children. Social workers on the other hand might have been more prone to report problems as a result of their professional training, their role as caregivers rather than parents or because they have other expectations with regard to the adolescents' behaviour (Thommessen et al., 2013).

As it has already been noted, most studies have relied on self-reports, but there are also studies based on medical records. A German study that investigated the physical and mental disease burden among 102 URM found that about one in ten of the male minors reported that they drank alcohol and/or consumed cannabis (Marquardt et al., 2016). A Swedish study based on patient records (Ramel et al., 2015) compared inpatient psychiatric care among URM and other adolescents, respectively. The findings from this study indicated that URM were overrepresented in inpatient psychiatric care. A comparison showed no diagnostic differences in mental and behavioural disorders due to psychoactive substance use between the groups; however, URM reported significantly more neurotic, stress-related and somatoform disorders.

Manhica et al. have published two studies based on Swedish national registers which examine patterns of hospital admissions due to alcohol disorders (Manhica et al., 2017) and hospital admissions and criminal convictions associated with substance misuse (Manhica et al., 2016) among refugees who settled in Sweden as teenagers. Hospital admissions due to alcohol disorders were less common among young refugees than among native Swedes. However, unaccompanied refugees were at higher risk of hospitalisation due to alcohol-related disorders by comparison with their accompanied peers (Manhica et al., 2017). When hospital care and criminal convictions associated with substance abuse were examined, the authors found that unaccompanied male refugees were at higher risk of criminality and hospital care associated with substance abuse than native Swedish males. For young unaccompanied females, on the other hand, the pattern was reversed. There was also an association between time of residency and hospital care and criminality related to substance use - the longer the male refugees had resided in Sweden, the higher the risk of substance use. The patterns were similar for accompanied refugees. However, it is important to note that, in contrast to the other studies discussed in this section, Manhica et al. $(2016,2017)$ examine substance use in adulthood, even though the selection criteria for the study population were focused on young refugees who had settled in Sweden as teenagers. 


\section{Contexts associated with drug use and criminality}

Some of the articles discuss substance abuse in terms of self-medication, i.e. in terms of alcohol or drugs being used by the URM to cope with painful experiences, mental health problems or the challenges of integrating into a new society (e.g. Deveci, 2012; Luster et al., 2010; Manhica et al., 2017). For example, in a study of successful adaptation among unaccompanied Sudanese minors in the USA, Luster et al. (2010) found that both the minors and their foster parents viewed substance/alcohol use as a common problem among adolescents who had been less successful. Both minors and foster parents associated substance use with mental health problems, and thought of it in part as a means of coping with painful memories of war experiences, but also as a way of handling stress associated with worries about relatives and with the need to succeed in school in order to get a job and support those left behind (Luster et al., 2010; see also Qin et al., 2015). In addition to explanations associated with mental health problems, the minors themselves explained the substance use of some of their Sudanese friends as a sign of adapting to the lifestyle of American youth. Manhica et al. (2017) also discuss adaptation to the drinking culture of the resettlement country (i.e. Sweden), and argue that the increased risk for hospitalisation due to alcohol-related disorders found among unaccompanied refugees might be explained by a lack of social control from parents or other adult family members, factors which might otherwise serve as a protection against risky behaviours.

In a couple of studies, post-migration challenges were considered in relation to drugs and criminality. For example, in Auger-Voyers and colleagues (2014) study on URM in the Canary Islands, the youths discuss their future and the types of job they would like to do, and one of the boys says that he would like to be a carpenter, but that selling drugs is probably a more realistic alternative. In a study of URM in South Africa, Magqibelo et al. (2016) note that on arrival in the country of asylum, the situation for many URM does not turn out as they have planned. Some of them end up in homelessness and on the streets, which may in turn lead to involvement in criminal activities. Herz and Lalander (2017), in a study of the ways in which URM talk about Ioneliness, refer to one boy who had experienced a tough time following his arrival in Sweden, and who during this period had started to drink a large amount of alcohol and to smoke hashish. What helped him during this period was that he came into contact with an activist group that engaged in his case and supported him in his contacts with the authorities. This led him to feel that someone cared for him, which in turn gave him hope for the future.

Manhica et al. (2016) found that the risk for hospital care and criminal convictions related to substance misuse among refugees decreased following controls for income. This can be seen as an indication of adverse living conditions among refugees in Sweden. The authors argue that this might play an important part in the explanation of their heightened risk of substance misuse (Manhica et al., 2016). The study measured substance misuse in adulthood and showed that refugees were more likely to live in segregated low-income neighbourhoods in which there is more access to illicit substances. However, this might also be applicable to refugee children and adolescents, both accompanied and unaccompanied.

\section{The importance of access to appropriate care}

One conclusion that is drawn in several of the studies included in this review is that interventions aimed at providing support to URM suffering from mental health problems are crucial, as are properly trained care workers and valid diagnostic instruments (Bean et al., 2007a; Derluyn and Broekaert, 2007; Marquardt et al., 2016; Oppedal and Idsoe, 2012; Thommessen et al., 2013). Mental health problems among URM risk going unnoticed as a result of the absence of parents or permanent caregivers, and in the literature it is argued that screening for mental health problems and access to mental health care are needed at reception. Poor care in the resettlement countries, together with social marginalisation and antisocial peers, might increase the risk for the development of antisocial behaviour among URM (Given-Wilson et al., 2016). Luster et al. (2010) conclude their study on adaptation among unaccompanied Sudanese minors in the USA by noting that "since substance abuse and mental health problems can be significant barriers to successful adaptation, it is important that service providers find ways to overcome the cultural stigma and offer culturally appropriate support for those experiencing problems" (p. 208). 
And even though none of the minors in the study by Huemer et al. (2011) were identified as having substance abuse problems, and only a few could be diagnosed with externalising behaviour, the authors argue that with regard to the high levels of PTSD and related internalising psychopathology, appropriate interventions targeting these problems might also prevent the development of more serious social problems such as delinquency and substance use.

Huemer et al. (2009) argue that a developmental approach is necessary for understanding the needs of URM. Such an approach recognises that maturity can in many cases lead to healing, but also that many of these adolescents need medical interventions, and that a risk-resilience model is required to understand the processes leading up to mental health problems. The authors argue that the same personality characteristics that help these adolescents to deal with the stress associated with the migration process and that protect them against the development of PTSD might also make them vulnerable to antisocial life trajectories (Huemer et al., 2009).

One Swedish study that examines the philosophy behind the reception of URM contains a story about a boy running away from the group residence in which he lived (Norström and Gustafsson, 2010). When his contact person was able to reach him, he was either very drunk or high on drugs. According to the authors' study, this incident led to the boy losing his guardian, and when he got into a fight and was reported to the police a few weeks later, he had no one who could support him. In relation to this example, the authors emphasise the need for unaccompanied children to have someone to confide in, someone who will listen to them, and a reception process that involves confirming the young person as an individual (Norström and Gustafsson, 2010).

Several articles point to the importance of primarily viewing URM as children and not primarily as migrants or refugees (e.g. Huemer et al., 2009). The rights of unaccompanied children differ between countries, but the main point is that ensuring them the same rights to care and support is the only way to begin to address the needs of this group and, in doing so, to prevent a possible negative development. In addition, Nordgren (2017) has argued that the focus on drug abuse among URM in Sweden over recent years might rather be seen as an attempt to construct a category of drug users based on the essentialising notions of culture and ethnicity.

\section{Discussion}

This overview of the ways in which drug use and criminality among URM have been addressed and discussed in the international research literature shows that these issues have not attracted very much attention. When the occurrence of drug use and/or criminality is discussed, it is often in relation to mental health problems and in terms of self-medication, i.e. the use of alcohol or drugs among URM as a means of coping with painful experiences or mental health problems, but also in relation to the challenges of integrating into a new society, difficulties finding work, unsuitable living conditions and a lack of social support.

A majority of the studies included in this review that measure drug use and criminality/ delinquency/antisocial behaviour have found that problems of these kinds are rare among URM (e.g. Derluyn and Broekaert, 2007; Huemer et al., 2011; Oppedal and Idsoe, 2012). This finding appears to puzzle some of the authors, who discuss it in terms of that the unaccompanied children perhaps being unwilling to report behaviours that might be considered undesirable (Derluyn and Broekaert, 2007; Huemer et al., 2011). An alternative explanation might be that the instruments employed in the studies are not adequate to capture externalising problems in this particularly vulnerable group. This possible disregard of externalising problems, together with a failure to treat internalising problems, might produce an increased risk for the development of antisocial behaviour. This increased risk is acknowledged by some of the studies included in this review (e.g. Given-Wilson et al., 2016; Huemer et al., 2011; Marquardt et al., 2016; Thommessen et al., 2013).

Huemer et al. (2009) have argued that it is important to apply a developmental perspective in order to improve the knowledge on URM life trajectories and on how these are affected by individual and contextual factors. Disregarding mental health problems, or early signs of antisocial behaviour, or being unable to provide appropriate care increases the risk for a negative development. Manhica et al. $(2016,2017)$ show that time appears to be an important aspect in 
the development of substance abuse among individuals who have arrived in Sweden as URM - the risk of criminal convictions and hospital care associated with substance abuse, and hospital admissions for alcohol-related disorders, increased with the length of stay in Sweden. However, the individuals in these studies arrived in Sweden in 2004 or earlier, since then the number of URM applying for asylum in Sweden, and the rest of Europe, has increased significantly, and in parallel with this increase many European countries have introduced more restrictive immigration policies. As a consequence, the conditions for URM in Europe have changed. Conditions also vary significantly between countries with regard to the legislation and the organisation of reception and care. Studies following the same individuals over time will provide an important contribution to our understanding of how different individual characteristics, in interaction with contextual circumstances, influence the developmental pathways of URM.

Most of the research reviewed in the present study focuses on minors who are part of the system in one way or another, i.e. they are involved with the social services, they have somewhere to live, etc. This lack of research on URMs who, for different reasons are not part of the system, is important to acknowledge, since this group might run an increased risk of being exposed to situations in which they may be involved in criminal activities or become addicted to drugs. This has been stressed in relation to children on the move who for one reason or another have found themselves halted on their way through Europe, stuck in places where they risk being exploited in different ways and forced to become involved in illegal activities (Beise et al., 2017; Digidiki and Bhabha, 2017). In addition, there are children who have never applied for asylum, children who are victims of human trafficking and persons who, for different reasons, are no longer considered children, and as a consequence no longer have access to the same recourses and support as underage children. There are several ethical and methodological challenges associated with research on URM outside of the system (cf. van Liempt and Bilger, 2018); nevertheless, this is clearly an issue that needs to be explored in future research.

\section{Conclusion}

The lack of research on issues related to substance abuse and criminality among URM may be a consequence of the fact that substance abuse and criminality are not substantial problems within this group. At the same time, this review shows that several researchers have emphasised that untreated mental health problems, stressful living conditions and a lack of support and control might put these children at risk for substance abuse and criminality, and this suggests a need for further research in this area. At the same time, following the reasoning of Nordgren (2017), it is important not to turn substance abuse and criminality among unaccompanied children into a question of ethnicity. It is important to recognise that within this group there are individuals with several coexisting risk factors, such as a lack of social support and control, vulnerability due to their past and present experiences, adverse living conditions and exposure to social settings that might encourage substance abuse and criminality. Nevertheless, this is a group of children and young adults whose unique experiences need to be recognised.

Findings from this review suggest that untreated mental health problems, stressful living conditions, and the lack of support and control might put URM at risk for substance abuse and criminality. These results are important for practitioners working with URM, such as health care, social services, school and the police. Close collaboration is needed to acknowledge problems at an early stage and to provide appropriate care. With regard to the scientific community, these findings clearly show that this is an area that calls for further research.

\section{Note}

1. In the research literature and also in governmental documents and reports from non-governmental organisations, different terms are used when discussing children who migrate alone (e.g. unaccompanied refugee children, unaccompanied migrant minors, unaccompanied asylum-seeking children, separated children, etc.). Throughout this article we will use the term unaccompanied refugee minors (URM). 


\section{References}

Aebi, M., Giger, J., Plattner, B., Metzke, C.W. and Steinhausen, H.-C. (2014), "Problem coping skills, psychosocial adversities and mental health problems in children and adolescents as predictors of criminal outcomes in young adulthood", European Journal of Adolescent Psychiatry, Vol. 23 No. 5, pp. 283-93.

Andersson, R. (2016), "Irreguljär migration och Europas gränskontroller. En etnografisk analys", Rapport 2016:3, Delmi, Stockholm, available at: www.delmi.se/\#!/nyheter/europas-granskontroller-i-dagoch-i-framtiden-1 (accessed 14 August 2019).

Armstrong, T.D. and Costello, E.J. (2002), "Community studies on adolescent substance use, abuse, or dependence and psychiatric comorbidity", Journal of Consulting and Clinical Psychology, Vol. 70 No. 6, pp. 1224-39.

Auger-Voyer, V., Montero-Sieburth, M. and Perez, L.C. (2014), "Chasing the European dream: unaccompanied African youths' educational experience in a Canary Islands' reception centre and beyond", Education Policy Analysis Archives, Vol. 22 No. 76, pp. 1-19.

Barnombudsmannen (2017), "Ensamkommande barn som försvinner", available at: www. barnombudsmannen.se/globalassets/dokument-for-nedladdning/publikationer/publikationer2/rapport_ ensamkommande_barn_som_forsvinner_2017.pdf (accessed 5 May 2019).

Bean, T., Mooijaart, A., Eurelings-Bontekoe, E. and Spinhoven, P. (2007), "Validation of the teacher's report form for teachers of unaccompanied refugee minors", The Journal of Nervous and Mental Disease, Vol. 195 No. 4, pp. 288-97.

Bean, T., Derluyn, I., Eurelings-Bontekoe, E., Broekaert, E. and Spinhoven, P. (2007a), "Comparing psychological distress, traumatic stress reactions, and experiences of unaccompanied refugee minors with experiences of adolescents accompanied by parents", The Journal of Nervous and Mental Disease, Vol. 195 No. 4, pp. 288-97.

Bean, T., Derluyn, I., Eurelings-Bontekoe, E., Broekaert, E. and Spinhoven, P. (2007b), "Validation of the multiple language versions of the hopkins symptom checkhst-37 for refugee adolescents", Adolescence, Vol. 42 No. 165, pp. 51-71.

Bean, T.M., Eurelings-Bontekoe, E. and Spinhoven, P. (2007), "Course and predictors of mental health of unaccompanied refugee minors in the Netherlands: one year follow-up", Social Science and Medicine, Vol. 64 No. 6, pp. 1204-15.

Beise, J., Grojec, A., Hansen, C.B., Matthes, J., Rosengaertner, S. and You, D. (2017), "A child is a child: protecting children on the move from violence abuse and exploitation", available at: www.unicef.org/ publications/files/UNICEF_A_child_is_a_child_May_2017_EN.pdf (accessed 5 May 2019).

Bryan, C. and Denov, M. (2011), "Separated refugee children in Canada: the construction of risk identity", Journal of Immigrant \& Refugee Studies, Vol. 9 No. 3, pp. 242-66.

Carlson, B.E., Cacciatore, J. and Klimek, B. (2012), "A risk and resilience perspective on unaccompanied refugee minors", Social Work, Vol. 57 No. 3, pp. 259-69.

Çelikaksoy, A. and Wadensjö, E. (2017), "Refugee youth in Sweden who arrived as unaccomapnied minors and separated children", Journal of Refugee Studies, Vol. 30 No. 4, pp. 530-53.

Derluyn, I. and Broekaert, E. (2007), "Different perspectives on emotional and behavioural problems in unaccompanied refugee children and adolescents", Ethnicity and Health, Vol. 12 No. 2, pp. 141-62.

Derluyn, I. and Broekaert, E. (2008), "Unaccompanied refugee children and adolescents: the glaring contrast between a legal and a psychological perspective", International Journal of Law and Psychiatry, Vol 31 No. 4, pp. 319-30.

Derluyn, I., Broekaert, E. and Schuyten, G. (2008), "Emotional and behavioural problems in migrant adolescents in Belgium", European Child and Adolescent Psychiatry, Vol. 17 No. 1, pp. 54-62.

Derluyn, I., Mels, C., Educ, M. and Broekaert, E. (2009), "Mental health problems in separated refugee adolescents", Journal of Adolescent Health, Vol. 44 No. 3, pp. 291-7.

Deveci, Y. (2012), "Trying to understand: promoting the psychosocial well-being of separated refugee children", Journal of Social Work Practice, Vol. 26 No. 3, pp. 367-83. 
Digidiki, V. and Bhabha, J. (2017), "Emergency within an emergency. The growing epidemic of sexual exploitation and abuse of migrant children in Greece", available at: https://fxb.harvard.edu/preventing-abuseand-sexual-exploitation-of-child-migrants-in-greece/\%0Ahttp://files/552/preventing-abuse-and-sexual-ex ploitation-of-child-migrants-in-greece.html (accessed 5 May 2019).

Dishion, T.J. and Loeber, R. (1985), "Adolescent marijuana and alcohol use: the role of parents and peers revisited”, American Journal of Drug and Alcohol Abuse, Vol. 11 Nos 1-2, pp. 11-25.

Dupont, H.J.B.H.M., Kaplan, C.D., Verbraeck, H.T., Braam, R.V. and Van De Wijngaart, G.F. (2005), "Killing time: drug and alcohol problems among asylum seekers in the Netherlands", International Journal of Drug Policy, Vol. 16 No. 1, pp. 27-36.

Eide, K. and Hjern, A. (2013), "Unaccompanied refugee children - vulnerability and agency", Acta Paediatrica, International Journal of Paediatrics, Vol. 102 No. 7, pp. 666-8.

Eurostat (2018), "Asylum applicants considered to be unaccompanied minors - annual data", available at: https://ec.europa.eu/eurostat/tgm/refreshTableAction. do?tab=table\&plugin=1\&pcode=tps00194\& language=en (accessed 11 November 2018).

Fazel, M.D., Reed, R.V., Panter-Brick, C. and Stein, A. (2012), "Mental health of displaced and refugee children resettled in high-income countries: risk and protective factors", The Lancet, Vol. 379 No. 9812, pp. 266-82.

Folkhälsomyndigheten (2017), "Regeringsuppdrag att kartlägga narkotikavanor bland ensamkommande barn och unga", available at: www.folkhalsomyndigheten.se/globalassets/livsvillkor-levnadsvanor/ andts/narkotika/forebyggande-arbete/redovisning-av-regeringsuppdrag-s2017-02634-fs.pdf (accessed 3 May 2019).

Given-Wilson, Z., Herlihy, J. and Hodes, M. (2016), "Telling the story: a psychological review on assessing adolescents' asylum claims”, Canadian Psychology, Vol. 57 No. 4, pp. 265-73.

Hansson, J., Ghazinour, M. and Wimelius, M.E. (2015), "Police officers' use of discretion in forced repatriations of unaccompanied, asylum-seeking refugee children: balancing efficiency and dignity", International Journal of Social Work and Human Services Practice Horizon Research Publishing, Vol. 3 No. 3 , pp. 101-8.

Hawkins, E.H. (2009), "A tale of two systems: co-occurring mental health and substance abuse disorders treatment for adolescents", Annual Review of Psychology, Vol. 60 No. 1, pp. 197-227.

Hedlund, D. (2017), "Constructions of credibility in decisions concerning unaccompanied minors", International Journal of Migration, Health and Social Care, Vol. 13 No. 2, pp. 157-72.

Herz, M. and Lalander, P. (2017), "Being alone or becoming lonely? The complexity of portraying 'unaccompanied children' as being alone in Sweden”, Journal of Youth Studies, Vol. 20 No. 8, pp. 1062-76.

Hodgins, S., Oliver, B.R., Tengström, A. and Larsson, A. (2010), "Adolescents who consulted for substance misuse problems: outcomes 1 year later", Nordic Journal of Psychiatry, Vol. 64 No. 3, pp. 189-95.

Huemer, J., Karnik, N. and Steiner, H. (2009), "Unaccompanied refugee children”, Lancet, Vol. 373 No. 9664 , pp. 612-14.

Huemer, J., Karnik, N., Voelkl-Kernstock, S., Granditsch, E., Plattner, B., Friedrich, M. and Steiner, H. (2011), "Psychopathology in African unaccompanied refugee minors in Austria", Child Psychiatry Human Development, Vol. 42 No. 3, pp. 307-19.

Huemer, J., Völkl-Kernstock, S., Karnik, N., Denny, K.G., Granditsch, E., Mitterer, M., Humphreys, K., Plattner, B., Friedrich, M., Shaw, R.J. and Steiner, H. (2013), "Personality and psychopathology in African unaccompanied refugee minors: repression, resilience and vulnerability", Child Psychiatry and Human Development, Vol. 44 No. 1, pp. 39-50.

Ivert, A.-K., Zyto, M., Adler, H., Torstensson Levander, M., Rydelius, P.-A. and Levander, S. (2017), "Criminality among former child and adolescent psychiatric patienst and matched controls", Open Journal of Medical Psychology, Vol. 6, pp. 16-30.

Jakobsen, M., Demott, M.A.M. and Heir, T. (2014), "Prevalence of psychiatric disorders among unaccompanied asylum-seeking adolescents in Norway", Clinical Practice \& Epidemiology in Mental Health, Vol. 10 No. 1, pp. 53-8. 
Jensen, T.K., Bjørgo Skårdalsmo, E.M. and Fjermestad, K.W. (2014), "Development of mental health problems - a follow-up study of unaccompanied refugee minors", Child and Adolescent Psychiatry and Mental Health, Vol. 8 No. 29, doi: 10.1186/1753-2000-8-29.

Jensen, T.K., Fjermestad, K.W., Granly, L. and Wilhelmsen, N.H. (2015), "Stressful life experiences and mental health problems among unaccompanied asylum-seeking children", Clinical Child Psychology and Psychiatry, Vol. 20 No. 1, pp. 106-16.

Kaunitz, C. and Jakobsson, J. (2016), "Ensamkommande barn och ungdomar placerade inom Statens institutionsstyrelse (SiS )”, Socialmedicinsk tidskrift, Vol. 93 No. 1, pp. 43-52.

Keles, S., Friborg, O., Idsoe, T., Sirin, S. and Oppedal, B. (2016), "Depression among unaccompanied minor refugees: the relative contribution of general and acculturation-specific daily hassles", Ethnicity \& Health, Vol. 21 No. 3, pp. 300-17.

Kohli, R. and Mather, R. (2003), "Promoting psychosocial well-being in unaccompanied asylum seeking young people in the United Kingdom”, Child \& Family Social Work, Vol. 8 No. 3, pp. 201-12.

Kohli, R.K.S. (2006), "The comfort of strangers: social work practice with unaccompanied asylum-seeking children and young people in the UK", Child and Family Social Work, Vol. 11 No. 1, pp. 1-10.

Länsstyrelsen (2016), "Lost in migration. A report on missing unaccompanied minors in Sweden", available at: www.lansstyrelsen.se/Stockholm/SiteCollectionDocuments/Sv/publikationer/2016/R2016-28-lost-inmigration-webb.pdf (accessed 7 May 2019).

Loeber, R., Farrington, D.P., Stouthamer-Loeber, M. and Van Kammen, W.B. (1998), Antisocial Behaviour and Mental Health Problems: Explanatory Factors in Childhood and Adolescence, Psychology Press, New York, NY.

Lundberg, A. and Dahlquist, L. (2012), "Unaccompanied children seeking asylum in sweden: living conditions from a child-centred perspective", Refugee Survey Quarterly, Vol. 31 No. 2, pp. 54-75.

Luster, T., Qin, D., Bates, L., Rana, M. and Lee, J.A. (2010), "Successful adaptation among Sudanese unaccompanied minors: perspectives of youth and foster parents", Childhood, Vol. 17 No. 2, pp. 197-211.

Magqibelo, L., Londt, M., September, S. and Roman, N. (2016), "Challenges faced by unaccompanied minor refugees in south africa", Social Work (South Africa), Vol. 52 No. 1, pp. 73-89.

Malmsten, J. (2014), "Unaccompanied children living in transitional houses - voices from Sweden", International Journal of Migration, Health and Social Care, Vol. 10 No. 1, pp. 18-35.

Manhica, H., Almquist, Y., Rostila, M. and Hjern, A. (2017), "The use of psychiatric services by young adults who came to Sweden as teenage refugees: a national cohort study", Epidemiology and Psychiatric Science, Vol. 26 No. 5, pp. 526-34.

Manhica, H., Gauffin, K., Almqvist, Y.B., Rostila, M. and Hjern, A. (2016), "Hospital admission and criminality associated with substance misuse in young refugees - a swedish national cohort study", PLoS ONE, Vol. 11, doi: 10.1371/journal.pone.0166066.

Manhica, H., Gauffin, K., Almquist, Y.B., Rostila, M., Berg, L., de Cortázar, A.R.G. and Hjern, A. (2017), "Hospital admissions due to alcohol related disorders among young adult refugees who arrived in Sweden as teenagers - a national cohort study", BMC Public Health, Vol. 17 No. 1, p. 644.

Marquardt, L., Krämer, A., Fischer, F. and Prüfer-Krämer, L. (2016), "Health status and disease burden of unaccompanied asylum-seeking adolescents in Bielefeld, Germany: cross-sectional pilot study", Tropical Medicine and International Health, Vol. 21 No. 2, pp. 210-8.

Moffitt, T.E. (1993), "Adolescence-limited and life-course-persistent antisocial behavior: a developmental taxonomy”, Psychological Review, Vol. 100, pp. 674-701.

Nordgren, J. (2017), "Making up the 'Drug-abusing immigrant': knowledge production in Swedish social work and drug treatment contexts, 1960s-2011", Contemporary Drug Problems, Vol. 44 No. 1, pp. 49-68.

Norström, E. and Gustafsson, K. (2010), "To receive with grace - the reception of separated, asylum-seeking minors arriving in Sweden”, Diskurs Kindheits- Und Jugendforschung, Vol. 5 No. 2, pp. 169-80.

Oppedal, B. and Idsoe, T. (2012), "Conduct problems and depression among unaccompanied refugees: the association with pre-migration trauma and acculturation", Anales de Psicología, Vol. 28 No. 3, pp. 683-94. 
Pettersson, M. (2016), "Polisens arbete med ensamkommande barn som begår brott", Socialmedicinsk tidskrift, Vol. 93 No. 1, pp. 37-42.

Piquero, A.R., Diamond, B., Jennings, W.G. and Reingle, J.M. (2013), "Adolescence-limited offending", in Gibson, C.L. and Krohn, M.D. (Eds), Handbook of Life-Course Criminology, Springer, New York, NY, pp. 129-42.

Qin, D.B., Saltarelli, A., Rana, M., Bates, L., Lee, J.A. and Johnson, D.J. (2015), “'My culture helps me make good decisions': cultural adaptation of sudanese refugee emerging adults", Journal of Adolescent Research, Vol. 30 No. 302, pp. 213-43.

Raghallaigh, M.N. and Gilligan, R. (2010), "Active survival in the lives of unaccompanied minors: coping strategies, resilience, and the relevance of religion", Child and Family Social Work, Vol. 15 No. 2, pp. 226-37.

Raghallaigh, M.N. and Thornton, L. (2017), "Vulnerable childhood, vulnerable adulthood: direct provision as aftercare for aged-out separated children seeking asylum in Ireland", Critical Social Policy, Vol. 37 No. 3, pp. 386-404.

Ramel, B., Täljemark, J., Lindgren, A. and Johansson, B.A. (2015), "Overrepresenta tion of unaccompanied refugee minors in inpatient psychiatric care”, SpringerPlus, Vol. 4 No. 131, doi: 10.1186/s40064-015-0902-1.

Seglem, K.B., Oppedal, B. and Roysamb, E. (2014), "Daily hassles and coping dispositions as predictors of psychological adjustment: a comparative study of young unaccompanied refugees and youth in the resettlement country", International Journal of Behavioral Development, Vol. 38 No. 3, pp. 293-303.

Sourander, A. (1998), "Behavior problems and traumatic events of unaccompanied refugee minors", Child Abuse \& Neglect, Vol. 22 No. 7, pp. 719-27.

Stretmo, L. (2014), "Governing the unaccompanied child - media, policy and practice", doctoral disertation, University of Gothenburg, Gothenburg.

Sundqvist, J., Ögren, K., Padyab, M. and Ghazinour, M. (2016), "Collaboration patterns among Swedish professionals in the repatriation of unaccompanied asylum-seeking refugee children: an explorative study", European Journal of Social Work, Vol. 19 No. 6, pp. 901-16.

Svensson, R. (2003), "Gender differences in adolescent drug use", Youth \& Society, Vol. 34 No. 3, pp. 300-29.

Swedish Migration Agency (2018), "Asylum applications 2000 to 2017", (Asylsökande till Sverige under 2000-2017), available at: www.migrationsverket.se/download/18.4a5a58d51602d141cf41003/151507632 6490/AsylsökandetillSverige2000-2017.pdf (accessed 11 November 2018).

Thevissen, P.W., Kvaal, S.I., Dierickx, K. and Willems, G. (2012), "Ethics in age estimation of unaccompanied minors", Journal of Forensic Odonto-stomatology, Vol. 3030 No. 11, pp. 22-4.

Thommessen, S., Laghi, F., Cerrone, C., Baiocco, R. and Todd, B.K. (2013), "Internalizing and externalizing symptoms among unaccompanied refugee and Italian adolescents", Children and Youth Services Review, Vol. 35 No. 1, pp. 7-10.

Uehling, G.L. (2008), "The international smuggling of children: coyotes, snakeheads, and the politics of compassion”, Anthropological Quarterly, Vol. 81 No. 4, pp. 833-71.

UNHCR (1994), "Refugee children: guidelines on protection and care preface”, available at: www.unhcr.org/ 3b84c6c67.pdf (accessed 11 November 2018).

van Liempt, I. and Bilger, V. (2018), "Methodological and ethical dilemmas in research among smuggled migrants", in Zapata-Barrero, R. and Yalaz, E. (Eds), Qualitative Research in European Migration Studies, IMISCOE Research Series, Springer, Cham, pp. 269-85.

Wagner, K. (2017), Pojkarna och de ensamma poliserna, Natur och kultur, Stockholm.

Wernesjö, U. (2011), “Unaccompanied whose perspective?”, Childhood, Vol. 19 No. 4, pp. 495-507.

Wernesjö, U. (2014), "Conditional belonging: listening to unaccompanied young refugees ' voices", doctoral disertation, Uppsala univeristet, Uppsala.

Wernesjö, U. (2019), "Across the threshold: negotiations 9" > of deservingness among unaccompanied young refugees in Sweden", Journal of Ethnic and Migration Studies, doi: 10.1080/1369183X.2019.1584701. 
Wikström, P.-O.H., Oberwittler, D., Treiber, K. and Hardie, B. (2012), Breaking Rules: The Social and Situational Dynamics of Young People's Urban Crime, OUP, Oxford.

Williams, B., Cassar, C., Siggers, G. and Taylor, S. (2016), "Medical and social issues of child refugees in Europe", Archives of Disease in Childhood, Vol. 101 No. 9, pp. 839-42.

Wimelius, M.E., Eriksson, M., Isaksson, J. and Ghazinour, M. (2017), "Swedish reception of unaccompanied refugee children - promoting integration?", Journal of International Migration and Integration, Vol. 18 No. 1, pp. 143-57.

\section{Further reading}

Länsstyrelsen (2018), “'Dekan alltid hitta mig’ studie om människohandel och utsatta barngruppers livsvillkor", available at: www.lansstyrelsen.se/download/18.276e13411636c95dd933a57/1526903019846/ Rapport\%202018-3\%20De\%20kan\%20alltid\%20hitta\%20mig.pdf (accessed 7 May 2019).

\section{Corresponding author}

Anna-Karin Ivert can be contacted at: anna-karin.ivert@mau.se

For instructions on how to order reprints of this article, please visit our website:

www.emeraldgrouppublishing.com/licensing/reprints.htm

Or contact us for further details: permissions@emeraldinsight.com 